\title{
Kinematics of the Danakil microplate
}

\author{
Graeme Eagles*, Richard Gloaguen, Cynthia Ebinger
}

Department of Geology, Royal Holloway University of London, Egham, Surrey, TW20 0EX, UK

Received 26 April 2002; received in revised form 5 July 2002; accepted 14 August 2002

\begin{abstract}
A refinement and extrapolation of recent motion estimates for the Danakil microplate, based on ancient kinematic indicators in the Afar region, describes the evolution of a microplate in the continental realm. The Danakil horst is an elevated part of this microplate, exposing a Precambrian basement within the Afar depression, the site of the NubiaSomalia-Arabia triple junction. We compare evidence for strike- or oblique-slip faults in data from the Afar depression and southern Red Sea to small circles about published poles of rotation for the Danakil microplate with respect to Nubia. A reconstruction about the preferred pole reunites lengths of a Precambrian shear zone on the Nubia and Danakil sides and preserves a uniform basement fabric strike through Nubia, Danakil and Yemen. Since at least magnetic chron C5 ( 11 Ma) Danakil rotated about a different pole with respect to Nubia than either Somalia or Arabia, but between chrons C5 and C2A Nubia-Danakil motion was a close approximation to NubiaSomalia motion. Since C2A relative motions of the Danakil microplate have been independent of movements on any of the neighbouring plate boundaries. We relate this to the onset of oceanic-type accretion within Afar. The resulting eastwards acceleration of Danakil was accommodated by westwards propagation of the Gulf of Aden rift that became the new, discrete, plate boundary between the Danakil microplate and the Somalia plate. Present-day activity suggests that the Red Sea and Aden rifts will link through Afar, thereby isolating the Danakil horst as a microcontinent on the Arabian margin.
\end{abstract}

(C) 2002 Elsevier Science B.V. All rights reserved.

Keywords: plate tectonics; Red Sea; Afar Depression; microplates

\section{Introduction}

Plate tectonics has led to the discovery of mi-

\footnotetext{
* Corresponding author. Present address: Alfred Wegener Institute for Polar and Marine Research, Postfach 120161, Bremerhaven D-27515, Germany. Tel.: +49-471-4831-1213; Fax: +49-471-4831-1149.

E-mail addresses: geagles@awi-bremerhaven.de (G. Eagles), r.gloaguen@gl.rhul.ac.uk (R. Gloaguen),

c.ebinger@gl.rhul.ac.uk (C. Ebinger).
}

croplates. The evidence for their kinematics is best preserved in the oceans and at their margins, where they are often shown to have had a brief, simple, existence governed by local complications to the major plate pattern (e.g. plate boundary jumps or migration of triple junctions) [1,2]. Within deforming continental regions, where the age of each kinematic indicator must be independently assessed, the process of microplate formation is poorly understood (e.g. [3,4]).

Nonetheless, due to their simplicity and predictiveness, models of plate kinematics are valuable 
adjuncts to geological investigation of continental microplate regions, which are characteristically complex (e.g. the Falkland Plateau, Weddellia, the Australian margins, and the Caribbean). Of wide significance are the minor motions of small plates at the Mesozoic to Recent Pacific margin of Antarctica (e.g. [5]) that have long hindered attempts to close the global plate circuit with the Pacific Ocean. In turn, this has affected thoughts on hot-spot fixity and absolute palaeo-plate motions (e.g. [6]).

The Afar depression, part of the Oligocene-Recent Afro-Arabian rift systems of NE Africa, is one of the few localities worldwide where one may study the processes of microplate formation on land. At its eastern edge, the Danakil horst is a narrow, NW-trending ridge of Precambrian basement partly covered by Oligocene-Recent lavas of the Afar flood basalt province (e.g. [7,8]). Further

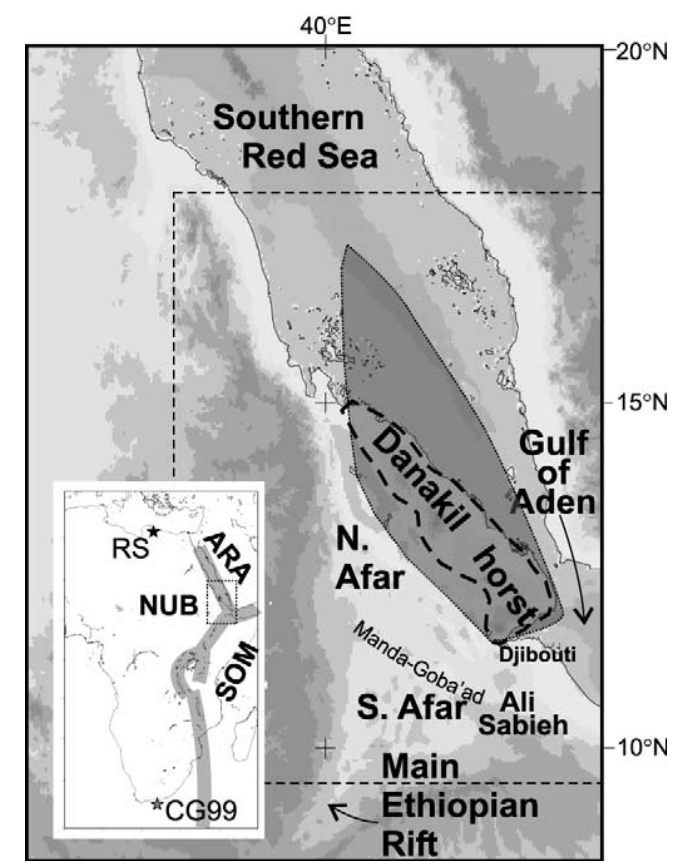

Fig. 1. 2-min-gridded topography. Manda-Goba'ad: trace of transform between northern and southern Afar. Shaded region: Danakil microplate [27], thick dashed black line: Danakil horst, dashed-outline box: domain of reconstructions in Fig. 2. Inset: Present plate tectonic setting; grey: extending regions, stars: instantaneous opening poles for Red Sea (RS [9]) and East African Rift (CG99 [15]). NUB: Nubia plate, SOM: Somalia plate, ARA: Arabia plate. east lies the southernmost Red Sea (Fig. 1). The 300-km-wide Afar depression is a diffuse extensional province marking a triple junction between the Arabia, Somalia and Nubia plates, where the Red Sea (Arabia-Nubia), the Gulf of Aden (Arabia-Somalia) and the Main Ethiopian rift (Somalia-Nubia) plate boundaries meet.

The Danakil horst was first suspected of being part of a microplate when reconstructions of the Red Sea in which it remains fixed with respect to Nubia caused it to overlap with Arabia (e.g. [7,9]). Courtillot and others [10,11] suggested that this overlap is the result of the variable stretching in continental crust of variable rheology by propagating rifts. The relative movements required for Danakil to lessen this overlap remain poorly known as kinematic data, until recently they have been restricted to Djibouti in SE Afar, a small part of the Afar depression. As a result, the Danakil-Afar region, which is probably also the best study locale for the early stages of continental breakup above a mantle plume, still lacks a well-constrained plate tectonic history.

We analysed satellite, air photo, seismic reflection, magnetic, gravity, topographic and geological data throughout the region shown in Fig. 1. We propose a new post-Oligocene plate kinematic model which is consistent with published global plate movements, and which can describe structural data from the Danakil-Afar region. We discuss the model in the context of formation of a microcontinent.

\section{Regional tectonic setting}

Two parallel NNW-trending rifts, the broad subaerial Afar depression and the southern Red Sea, had formed by Early Miocene times as Arabia separated from Africa (e.g. [12,13]; Fig. 1). Plate reconstructions and geodetic data show a NE-SW opening direction in the Red Sea and the Gulf of Aden parts of the Afar Depression. The NNE-trending Main Ethiopian rift is extending in a direction $\mathrm{N} 108^{\circ} \mathrm{E}$ at $4 \mathrm{~mm} \mathrm{a}^{-1}$ [14], consistent with predictions of global plate motion data ([15]; Fig. 1). The NW-striking Manda-Goba'ad fault zone acts as an incipient plate bound- 
ary connecting the southern and northern parts of the rift system in Afar which have been approximated to East African and Red Sea rifting, respectively (e.g. [13,16]). NE-directed seafloor spreading in the Gulf of Aden propagated westward towards and, recently, into the Afar depression since $25 \mathrm{Ma}$ [13]. NE-directed seafloor spreading in the Red Sea commenced at $\sim 4 \mathrm{Ma}$ ([17]; Fig. 1).

Sichler's model [18] for the opening of the Afar depression proposes that Danakil moved like a crank-arm between Euler poles at its northwestern and southeastern extremities, as though somehow 'pinned' there to the separating Nubia and Arabia plates, respectively. Others [19,20] suggested the eastward rotation of Danakil was accompanied by a similar, but opposite, movement of the Ali-Sabieh block (Fig. 1) to the south. The restricted geographical focus of later studies and their consideration of only Pliocene-Recent faults have given rise to conflicting assessments of the crank-arm model. Souriot and Brun [21] found the crank-arm model to be consistent with fault patterns in SE Afar. Neogene fault kinematic data in the Main Ethiopian rift (e.g. [22]) do not show the strike-slip or highly oblique-slip motions predicted by the crank-arm model. Three studies [2325] have attempted to relate block movements constrained by palaeomagnetic data from a few locales in SE Afar to 'duelling' rifts propagating into Afar from the Red Sea and the Gulf of Aden. The model of Acton and Stein [24] is consistent with the fault study in [21] but not with the crankarm model. Acton and others [25] presented further palaeomagnetic results that do not support the crank-arm model.

The kinematic model of Collet and others [26] (CEA in Fig. 2) shows independent movement of Danakil since an Oligocene inception. It incorporates the crank-arm model, but adds an early (pre-Miocene) phase of fast sinistral strike-slip between the Danakil horst and Nubia. This phase is introduced to remove Danakil from a gap in SW Afar when reconstructed using a least squares fit of the Arabian and Somalian coastlines and the limits of basement outcrops to those of the western Afar margin, which may not accurately mark the edges of the continental parts of the plates [9].
Although the model reunites African and Arabian Precambrian shear zones expressed in a digital terrain model, few of these features can be positively identified as throughgoing on Danakil itself.

Le Pichon and Francheteau [9] determined independent motions of Danakil by composition from total reconstructions of the southernmost Red Sea and the Gulf of Aden, but had to make assumptions about the shape of the continent-ocean boundaries in both systems. To avoid doing likewise, Chu and Gordon [27] analysed the most recent plate movements in the Red Sea region, based on seafloor spreading rates and on earthquake slip-vectors. As well as showing the approximate shape of the present-day Danakil microplate they gave Euler poles for motions in the region since magnetic anomaly chron $\mathrm{C} 2 \mathrm{~A}$ (about 3.2 Ma). These poles show that Danakil still has resolvable motions with respect to both Nubia and Arabia, and that the crank-arm model is not applicable to Danakil's post-C2A tectonic setting. However, the poles' $95 \%$ confidence ellipses contain a set of statistically significant alternatives that have rather different implications for Afro-Arabian rift kinematics and the evolution of the Afar plume province. This paper examines those alternatives.

\section{Method}

We assume initially that the Danakil horst should fit tightly to the west Afar margin in reconstructions. To rotate it we used representatives of the range of statistically significant instantaneous poles in [27]. These are simply taken from the centre and extremes of the semi-major axis of the preferred 95\% confidence ellipse about the instantaneous pole. Explicitly, given the very short timescale of movement and the fact that successive stage poles in plate tectonic systems tend to be closely spaced with respect to each other, we assume that these instantaneous poles will be close to reconstruction poles for times earlier than 3.2 Ma. For comparison we also used the total reconstruction poles of Le Pichon and Francheteau [9] and Collet and others [26]. The range of reconstructions is shown in Fig. 2. We were able imme- 

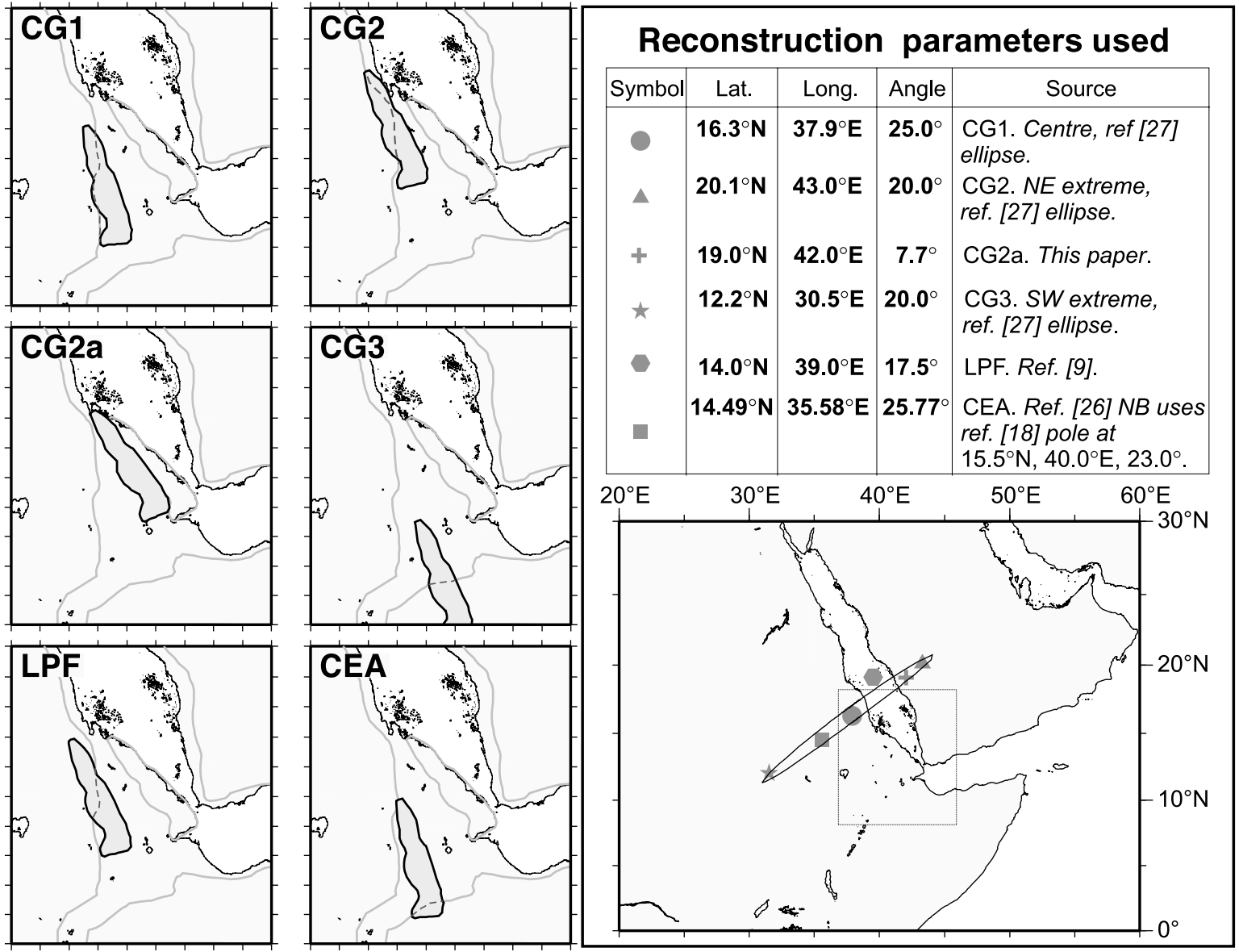

Fig. 2. Reconstructions of Danakil horst to the Afar western margin, using published reconstruction parameters (LPF, CEA; $[9,26])$ or instantaneous poles and rotations in the published sense, but sufficient to tightly align the horst with one of Afar's margins (CG1-3; [27]). Tick-mark spacing: 1 degree. Regional map shows the preferred 95\% confidence ellipse of [27], the poles (filled shapes) and domain of the reconstructions (box). The table summarises the rotation parameters. To make the reconstructions the rotations are applied in a left-handed sense.

diately to reject the reconstruction about a pole (CG3) at the southwestern extreme of the ellipse, since it results in an unacceptable overlap of the Danakil horst with the Somalia plate. The remaining reconstructions fall into two classes, with reconstruction poles near the centre (CG1) and near the northeastern extremity (CG2) of the ellipse. In the CG1 class of reconstructions, that share qualities with the reconstructions of Le Pichon and Francheteau [9], and the crank-arm family of reconstructions [18,26], Danakil disperses from the southern part of the west Afar margin in a northeasterly direction. This position enables attempts at 'tight' closure (i.e. coastlineto-coastline reconstruction of Arabia and Nubia) with the simplest, two-plate, sense of opening for Afar, albeit with some overlap of Danakil and the west Afar margin. In the CG2 class, Danakil disperses from the north of the margin towards the SE, and 'tight' closure is not possible without considering other movements within Afar. The two classes produce reconstructions of the Danakil horst that are separated from one another by as much as $350 \mathrm{~km}$ along the Afar margin.

In qualitative terms the sense of movement in the CG1 class of reconstructions might be ex- 
pressed as the result of undoing extension at a propagating ridge-tip, offset from the southernmost Red Sea, which is interacting with that in the Gulf of Aden. This is an intuitively attractive model from which block rotations within parts of Afar have been successfully predicted [23,24]. However, it is difficult to explain why a Danakil microplate should have been initiated and should continue to exist in such an otherwise simple situation, especially because the Red Sea spreading centre remains well-established morphologically and energetically to the east of Danakil from $\sim 18^{\circ} \mathrm{N}$ to $14.5^{\circ} \mathrm{N}$ (Fig. 1). That is, why should a $>200-k m-l o n g$ relay zone exist on the Red Sea ridge, instead of a simple transform? The CG2 class of reconstruction has no immediate intuitive appeal. Nonetheless, it uses a pole that is almost as well-constrained as CG1. Bearing in mind that we are assuming the pre-C2A relevance of the parameter set in [27], both classes deserve further attention.

Our test procedure is to predict the orientation of tectonic structures due to plate movements about the reconstruction poles, in order to compare trends in existing data sets. We predict structural trends by calculating small circles about each of the poles. These should correspond to the azimuths of features acting purely in a strike-slip sense, or that were stationary on the flanks of extending rifts. Great circles, orthogonal to these, predict the orientation of pure dip-slip normal faults and magmatic dikes in extending areas. All these features will only be found in areas that have experienced Oligocene to Recent deformation. Fortuitously, pre-existing (Precambrian) regional structural trends are predominantly NE-NNE, oblique to the predicted extension directions about either CG1 or CG2, and so do not greatly confuse the analysis. As shown below, we find that the CG2 pole class predicts the azimuths of a large number of structures evident in geological and geophysical data. A small adjustment to the CG2 pole improves the quality of the overall fit (by inspection), while still remaining within the $95 \%$ confidence ellipse of [27] (Fig. 2; CG2a pole: $19.0^{\circ} \mathrm{N}, 42.0^{\circ} \mathrm{E}$ ).

In Fig. 3 we identify a set of topographic structures that are consistent with movement about the
CG2a pole. On the Nubia flank of the DanakilNubia boundary in Eritrea and Sudan a prominent set of deeply incised valleys is evident as small circles about the pole (the Dzara, Anseba, Himbol-Afabet and Cub-Cub lineaments). Geological mapping shows that these features express oblique-slip to strike-slip faults and basins associated with Oligocene-Miocene volcanism [29,30]. In the Danakil and Afar depressions a number of topographic steps, ridges and troughs follow small-circle trends (Figs. 3, 4). On Danakil itself, the conjugate margin to the Nubia margin, low relief topographic ridges express arcs of the same set of circles. They are also evident as bends in the Red Sea coastline.

An orthorectified mosaic of Landsat thematic mapper images (Fig. 4a) from the Afar region shows similar tectonic trends within the Afar depression. In Fig. 4b we show the right-handed steps between the Erta Ale and Alayta magmatic segments and between the Tendaho and Hanle basins as evidence for the influence of the CG2a pole in the northern and southern Afar regions, respectively. It is also present as narrow basins or segments of narrow curvilinear basins (e.g. Immino, Goba'ad). The Manda-Goba'ad discontinuity is sub-parallel to this trend. A simplified structure contour map to the top early Miocene reflector shows major NW-striking faults along the NE Danakil horst, but basin-bounding faults accommodating extension strike north. The Gulf of Aden rift has propagated NW through central and eastern Afar, taking the Danakil-SomaliaNubia triple junction with it, so that in this area Somalia-Danakil trends may be actively adopting and deforming pre-existing CG2a ones (Fig. 5). Conjugate fault arrays and Riedel shears aligned along a CG2a flowline trend (e.g. roughly along $12^{\circ} \mathrm{N}$ ) indicate a significant component of rightlateral slip distributed along extending sectors of this boundary. In support of our remote sensing studies, air photo and field data demonstrate that many of these structural features show strike-slip movements [32]. Many smaller faults have trends orthogonal to our model flowlines (Fig. 4). Outcrop studies show that these NNE- and N-striking dip-slip faults acted during the Oligocene-Miocene [33]. Away from central and eastern Afar, 


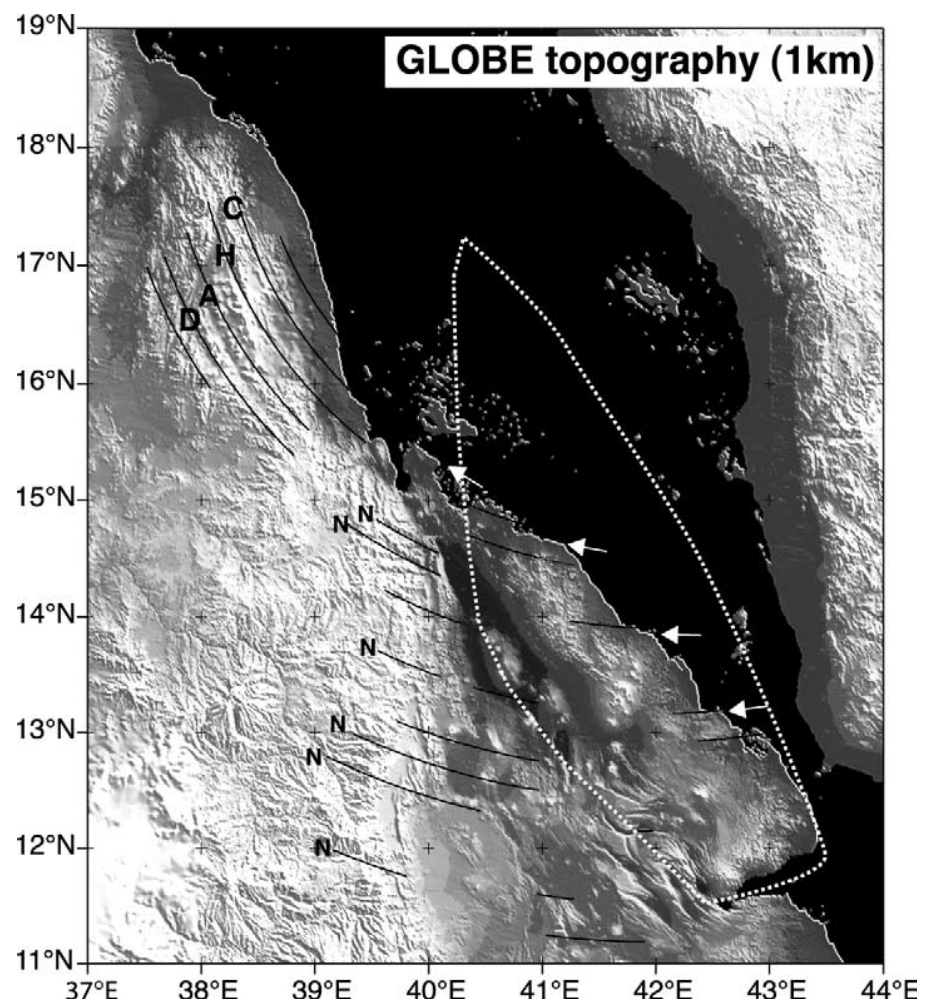

Fig. 3. 1-km topography [28] in the Afar region. Thin black lines: small circles about the CG2a pole, lineaments D: Dzara, A: Anseba, H: Himbol-Afabet, C: Cub-Cub, N: unnamed lineaments, white arrows: subdued topography on the Danakil horst, including lengths of its coastline, dashed white outline: Danakil microplate from [27].

where fault patterns reflect the changing plate boundary associated with the propagating Aden rift, lines of volcanoes fall along meridians to the CG2a pole. This disposition is consistent with their preferential formation along tensional features.

Basement lineations measured on the Landsat image (Fig. 6) have a strike on the northern Danakil horst similar to those on the Nubia and Arabian margins, which is consistent with the small $\left(\sim 7^{\circ}\right)$ anticlockwise rotation of such trends on Danakil implied by movement about the CG2a pole. The CG1 class of reconstructions, which treats Afar as a two-plate system and in which the rotation pole lies along strike from the Danakil horst itself, generally implies much larger rotations $\left(\sim 17.5-25^{\circ}\right)$.

Bouguer gravity and total field magnetic anomalies, which constrain the geometry of upper crustal structures, also show several prominent WNW- to NW-trending features parallel to predicted motions (Fig. 7a, b). An elongate Bouguer anomaly low, continuing the NW trend of the northern coastline of Danakil from its northernmost tip to the western Red Sea escarpment, represents a feature of considerable depth extent. Interpretations of industry seismic-reflection profiles NE of the Danakil horst show that the gravity and magnetic lineaments correspond to Early Miocene NW-striking faults showing oblique-slip movement ([34]; D.G. Roberts, personal communication, 2000) (Fig. 4b). This is consistent with the prominent anomaly accommodating Miocene-post-Miocene wrenching movements about the CG2a pole, as is the alignment, further along a CG2a small circle from the anomaly, of a small published set of dextral strike-slip nodal planes oriented $\sim \mathrm{S} 70^{\circ} \mathrm{E}[27]$. 

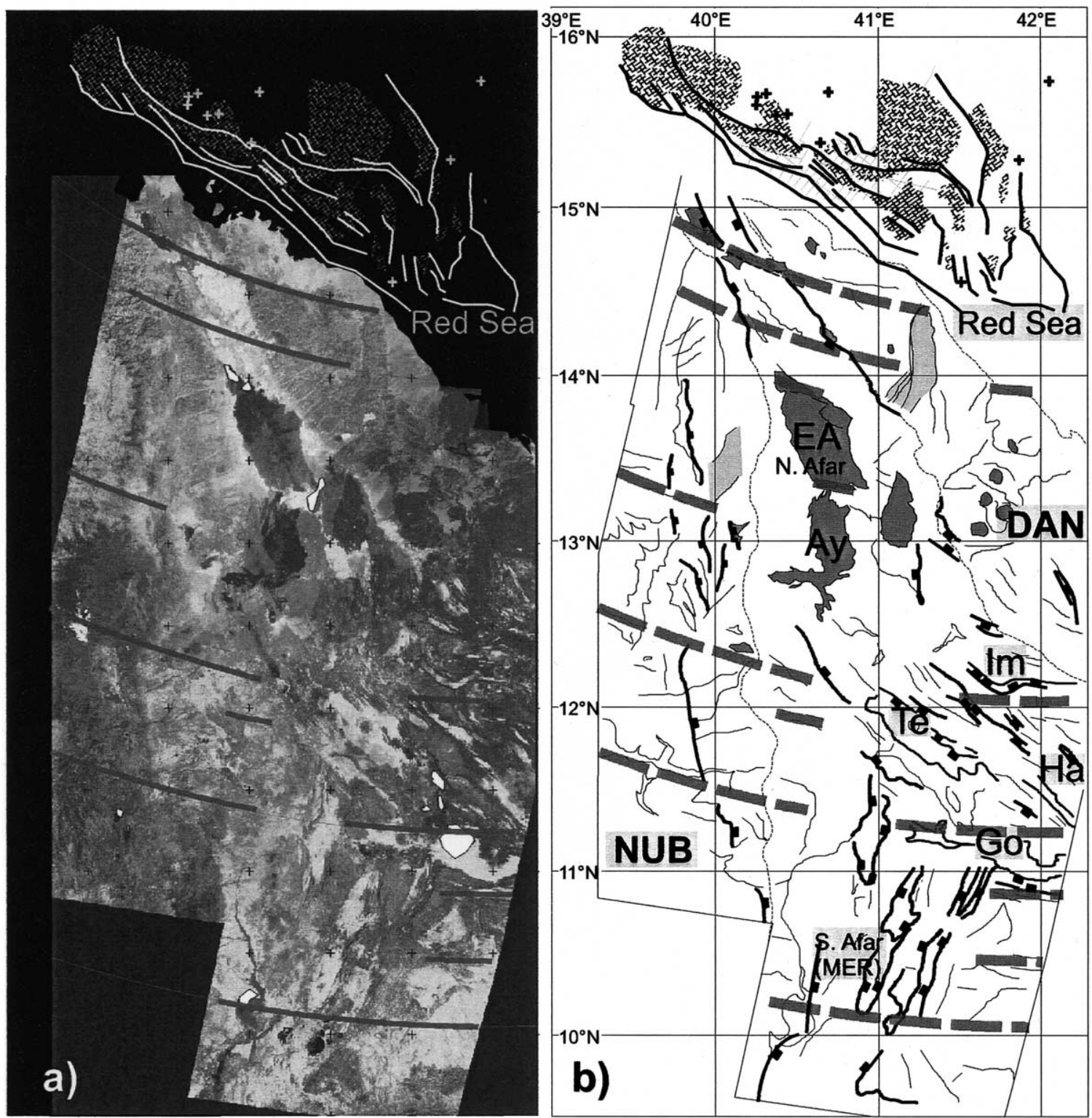

Fig. 4. (a) Landsat mosaic over Afar and its margins. Thick grey lines: small circles about the CG2a pole. (b) Thin black lines: undifferentiated features from the mosaic, thicker black lines with ticks: normal faults interpreted from the mosaic, thicker grey lines: CG2a small circles, dark grey fill: Quaternary volcanoes, lighter grey: lengths of pan-African shear zone, EA: Erta Ale volcano, Ay: Alayta volcano, DAN: Danakil, NUB: Nubia, Im: Immino basin, Te: Tendaho basin, Ha: Hanle basin, Go: Goba'ad, MER: section of the Main Ethiopian rift in southern Afar. Offshore features from seismic (light grey lines) and well (light grey crosses) data [D. Roberts, personal communication, 2000]; black lines: major faults, hatched regions: depocentres with $>3.6$ s TWTT Miocene-Recent strata. 


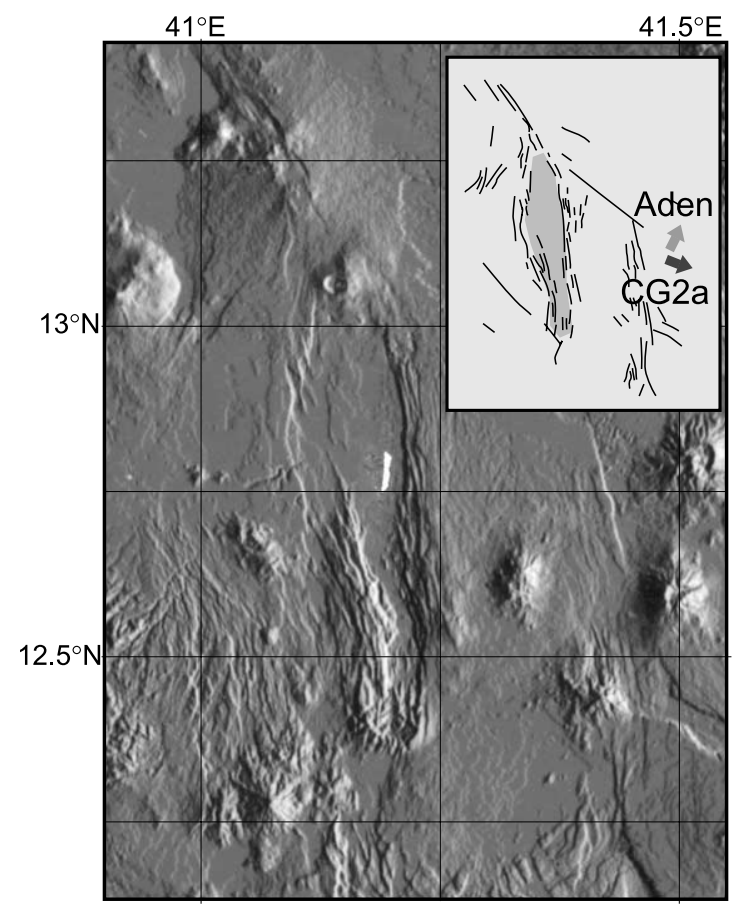

Fig. 5. Polyphase tectonics in Afar. Atypical sigmoid shape of the $\mathrm{N}-\mathrm{S}$ trending basin just west of $41.25^{\circ} \mathrm{E}$ can be explained by an initial phase of deformation producing NNEtrending faults (CG2a; inset), which have been reactivated by later NW-oriented movements between the Somalia and Danakil plates (Gulf of Aden propagation 'Aden'; inset). Similar sigmoid basins have been generated by analogue modeling of multiphase rift systems [31].

\section{Evolution of Afar}

A reconstructed sequence of plate movements provides insights into the development of a microcontinent within a flood basalt province. Fig. 8 shows reconstructions of the Afar depression region, using the CG2a pole. The reconstruction was produced by making an oblique Mercator projection of the satellite data, using CG2a as the axis of the projection. Since small circles about this will plot as horizontal lines on the map, moving the Danakil part of the data horizontally produces an accurate reconstruction.

Figure $8 \mathrm{a}$ shows a reconstruction at $3.2 \mathrm{Ma}$, made by assuming the extension rate in [27] to be applicable for movement about our CG2a pole. This reconstruction implies $36 \mathrm{~km}$ of ESEdirected movement between the western Afar escarpment and the Danakil horst at $14.5^{\circ} \mathrm{N}$, and 63 $\mathrm{km}$ at $11^{\circ} \mathrm{N}$, since $3.2 \mathrm{Ma}$. This implies extension at rates of 11-20 $\mathrm{mm} \mathrm{a}^{-1}$, comparable to full rates of ultra-slow to slow seafloor spreading, as seen for instance in the Red Sea just to the north.

Figure $8 \mathrm{~b}$ shows a reconstruction that visually realigns part of a Precambrian shear zone on the western Afar margin with its possible continuation on the northern Danakil horst. This fit requires that Danakil underwent $7.7^{\circ}$ right-handed rotation about $\mathrm{CG} 2 \mathrm{a}$. At the post-C2A rates of
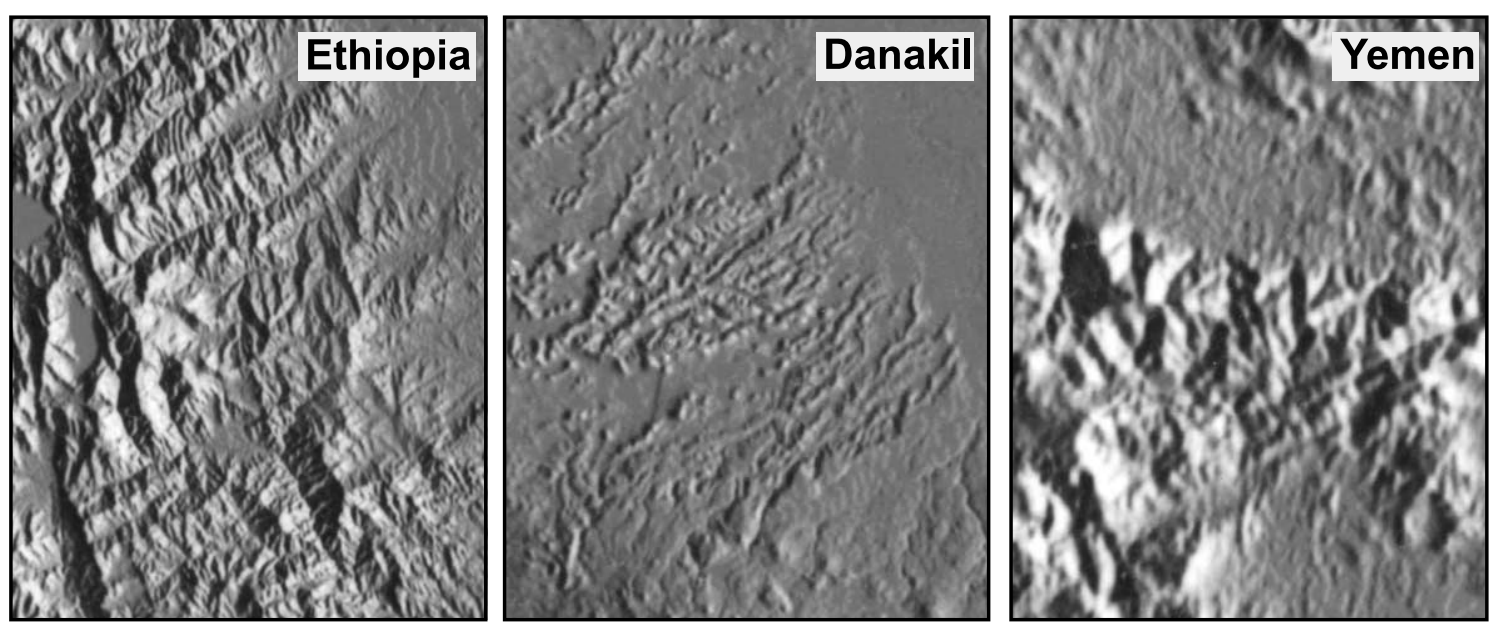

Fig. 6. Basement fabric trends measured on orthorectified Landsat images for Nubia, Danakil and Yemen. These trends are similar throughout, implying only minor rotations of the Danakil block and Arabian plate with respect to Nubia since the Oligocene. 


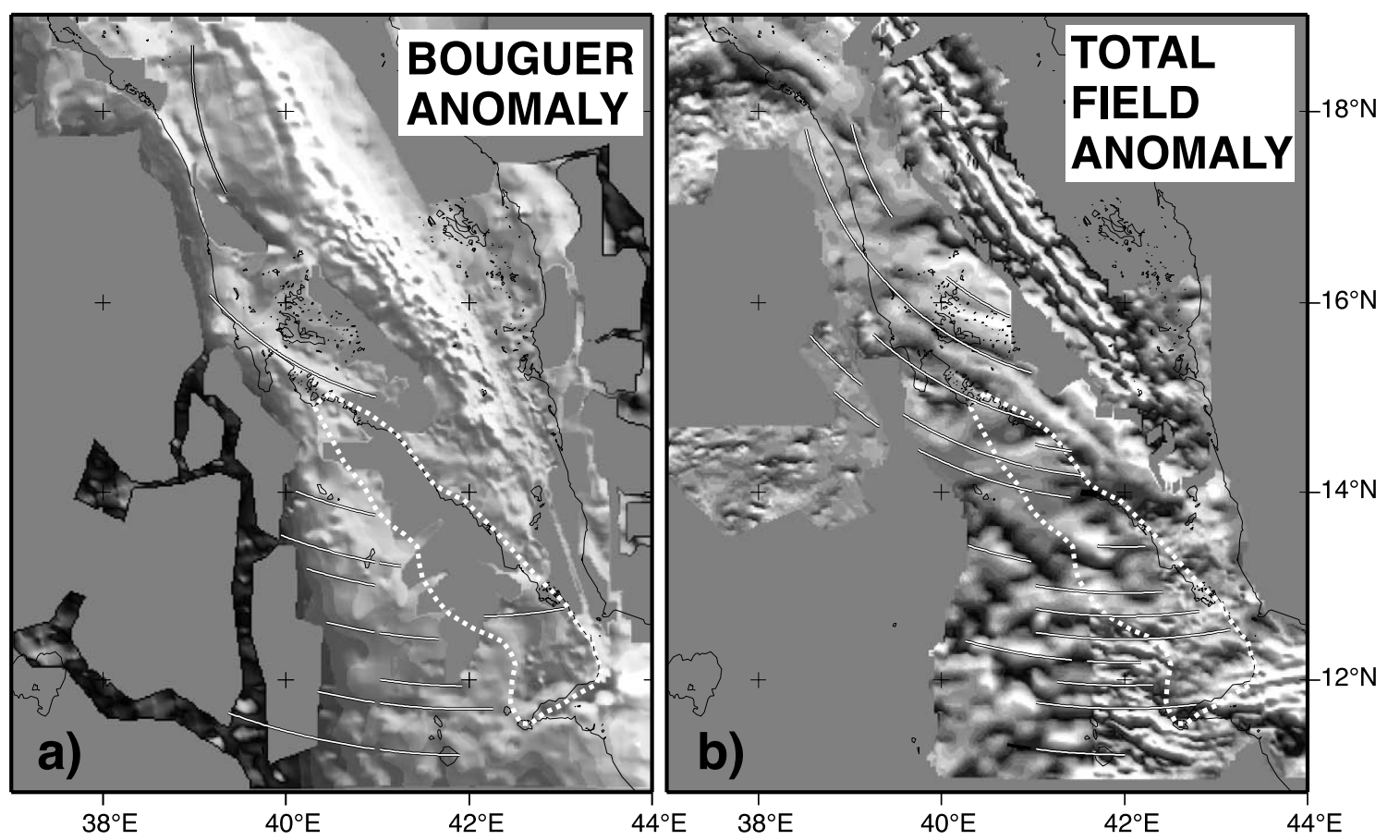

Fig. 7. (a) Afar Bouguer anomalies, light colours more positive. Black/white lines: CG2a small circles. (b) Afar total field magnetic anomalies, light colours more positive. Trends in these anomalies suggest that movements about the CG2a pole influence features of the Afar region's basement. The outline of the Danakil horst is included for orientation purposes.

angular separation discussed above, parting of the two branches of the shear zone, and earliest movements in northern Afar, would have occurred as recently as 6.3 Ma. This is not consistent with the Oligo-Miocene ( $\sim 25 \mathrm{Ma})$ determination of activity on the Anseba-Cub-Cub lineaments [30]. A very small average angular rate of $<0.2^{\circ}$ per million years in the pre-C2A period is more appropriate. This rate is roughly one sixth of the post-C2A rate [27], or $2-3.5 \mathrm{~mm}$ $\mathrm{a}^{-1}$ in northern and southern Afar, respectively. These values are comparable to those determined for the Main Ethiopian rift $\left(4 \mathrm{~mm} \mathrm{a}^{-1} ;[14]\right)$ and are consistent with field observations of OligoMiocene synrift strata along the Nubia margin in Ethiopia which show small degrees of extension $(\beta<1.2,[33])$.

It is evident from our reconstruction of Precambrian shear zones, as well as the modest angular rates calculated here and in [27], that tight-fit reconstructions of Danakil to the Afar margin due to a single two-plate Afar-extension episode (e.g.
CG1, CG2, CG3, LPF and CEA; Fig. 2) are inappropriate: they all feature excessive rotation of Danakil and an excess of extension for the observed rate and timescale in Afar. Nonetheless, our CG2a reconstruction exhibits open space within southern Afar, south of the Alayta volcanic segment (cf Figs. 2, 4). This densely faulted space may mostly be the product of non-rigidity within Afar and Danakil [35], during propagation of the Gulf of Aden rift after $5 \mathrm{Ma}$, hence its northward-tapering shape, but it is also partly occupied by undeformed blocks [24,25]. More of it can be accounted for, south of $12.5^{\circ} \mathrm{S}$, because we have not moved Somalia with respect to $\mathrm{Nu}$ bia, according to closure of the Main Ethiopian rift, at all in the reconstruction. In addition, an oblique opening of the early Red Sea, if it occurred [36], might tighten the reconstruction by occasioning shape changes or prior movements of Danakil and the margins. However, Fig. 8 illustrates none of these possibilities, since none of the other movements would have occurred about 

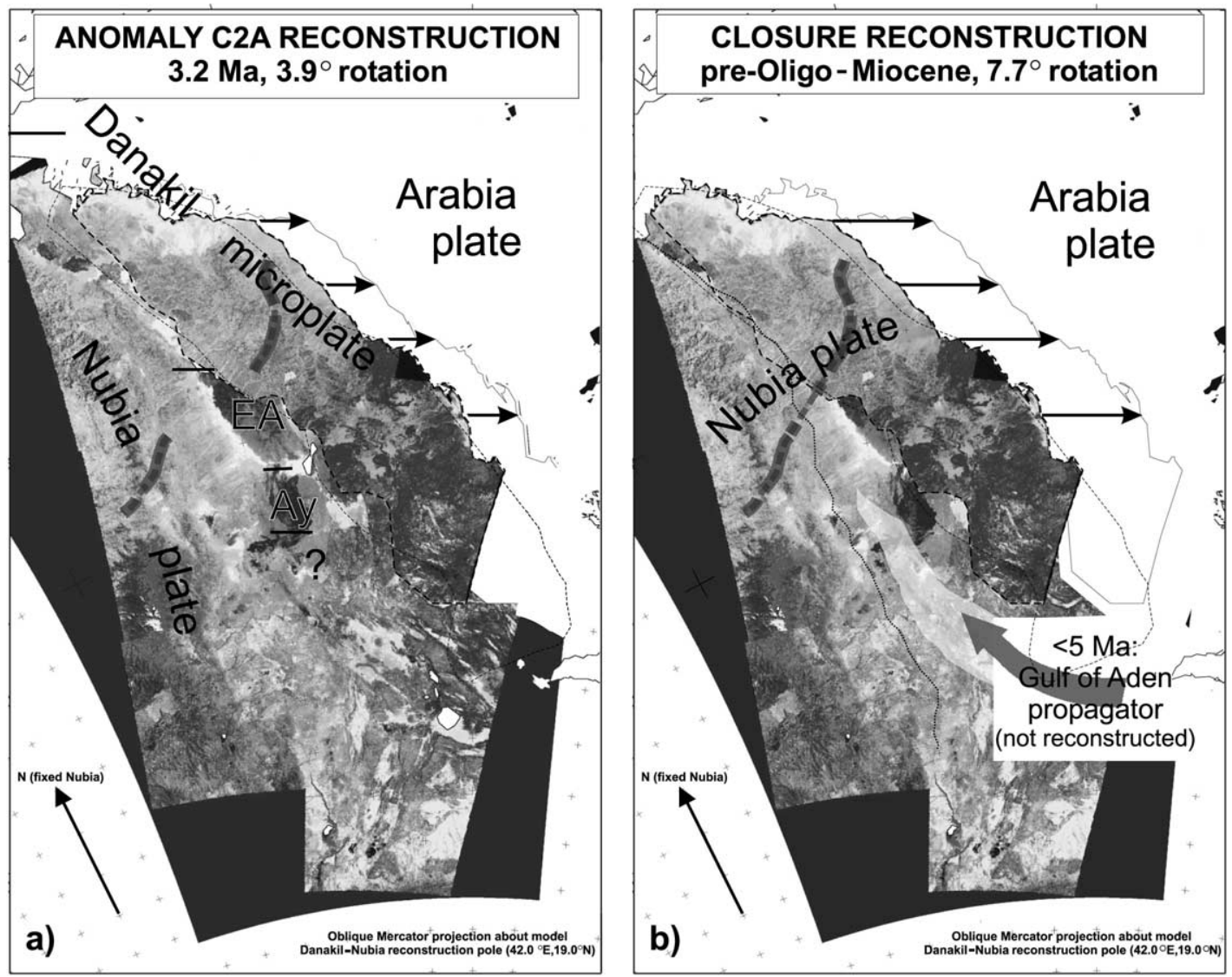

Fig. 8. Satellite imagery mosaic of Afar depression, (a) reconstructed at 3.2 Ma, showing transform faults and proto-magmatic segments at Erta Ale (EA) and Alayta (Ay). The palaeo-Danakil-Nubia boundary is hard to interpret south of the question mark, where Danakil-Somalia (Gulf of Aden) trends have overprinted it, (b) reconstructed at closure, prior to the Oligocene/ Miocene. Bold dashed line: Danakil horst outline from Landsat data, thin dashes: Danakil horst as in Fig. 2, for comparison, bold dotted line: west Afar margin from Landsat data, thin dotted line: present-day (unrotated) coastline, thick grey lines: branches of pan-African shear zone.

the CG2a pole (and so cannot be illustrated by horizontal translations on our oblique Mercator projection) and the outlines of the undeformed blocks are uncertain.

\section{Implications for microplate formation}

Given the large number of morphological and structural features matched by our CG2a pole model, we discuss the wider setting of Danakil horst motion. To the north and east of the Danakil-Afar region well-formed magnetic anomaly pairs show that the Red Sea and Gulf of Aden rifts have proceeded to full seafloor spreading [37-39]. To the south, in the East African Rift, relative motion has been very slight and GPS networks alone have either been too small or recently deployed to provide an instantaneous pole of rotation. Instead, relative movements between Somalia and Nubia have been constrained with external (seafloor spreading) data, assuming rigid three-plate circuits. C2A-Present 'instantaneous' poles are situated to the south of South Africa $[15,40]$, and a chron C5 finite pole is given in [41]. 


\subsection{Margins of the Danakil microplate}

Our CG2a pole is not strictly consistent with an assumption of three rigid plates in Afar at any time since chron C5 $(\sim 11 \mathrm{Ma})$ because it does not coincide with any published instantaneous or stage poles in the Somalia-Arabia-Nubia circuit. Hence, a Danakil microplate must have existed, with boundaries, since at least $11 \mathrm{Ma}$. The present-day boundary between the Danakil microplate and the Somalia plate is the Asal-Ghoubbet rift, where seafloor spreading initiated at about $0.7 \mathrm{Ma}$ and was preceded by extension since $\sim 5 \mathrm{Ma}[35,42,43]$. Younger lavas obscure evidence for Danakil-Somalia movements prior to $5 \mathrm{Ma}$. Also prior to $5 \mathrm{Ma}$, strain between Danakil and Arabia was accommodated across the Bab-elMandab Straits [42], but at present-day the straits are almost aseismic. Thus a Danakil microplate with a southern boundary like that of today could not have existed until the propagation of the Gulf of Aden rift into Afar after $5 \mathrm{Ma}$, and this seems to have been achieved at the expense of strain accommodation across the Bab-el-Mandab Straits. Fig. 9 compares total pre-chron-C2A movements in our reconstruction with those about the C5-C2A Somalia-Nubia stage pole calculated from references [15] and [41], to illustrate the qualitative similarity between Danakil-Nubia and Somalia-Nubia relative motions in those northern parts of Afar least affected by the recent Aden propagator. Given this, and acknowledging the uncertainties in our determination of the CG2a pole and the formal uncertainties in the poles of [15] and [41], it seems most likely that the small C5-C2A difference between Nubia-Somalia and Nubia-Danakil motions were due to minor movements across a nascent Somalia-Danakil boundary. We suggest, therefore, that even earlier movements of Danakil occurred essentially as a rigid part of the Somalia plate.

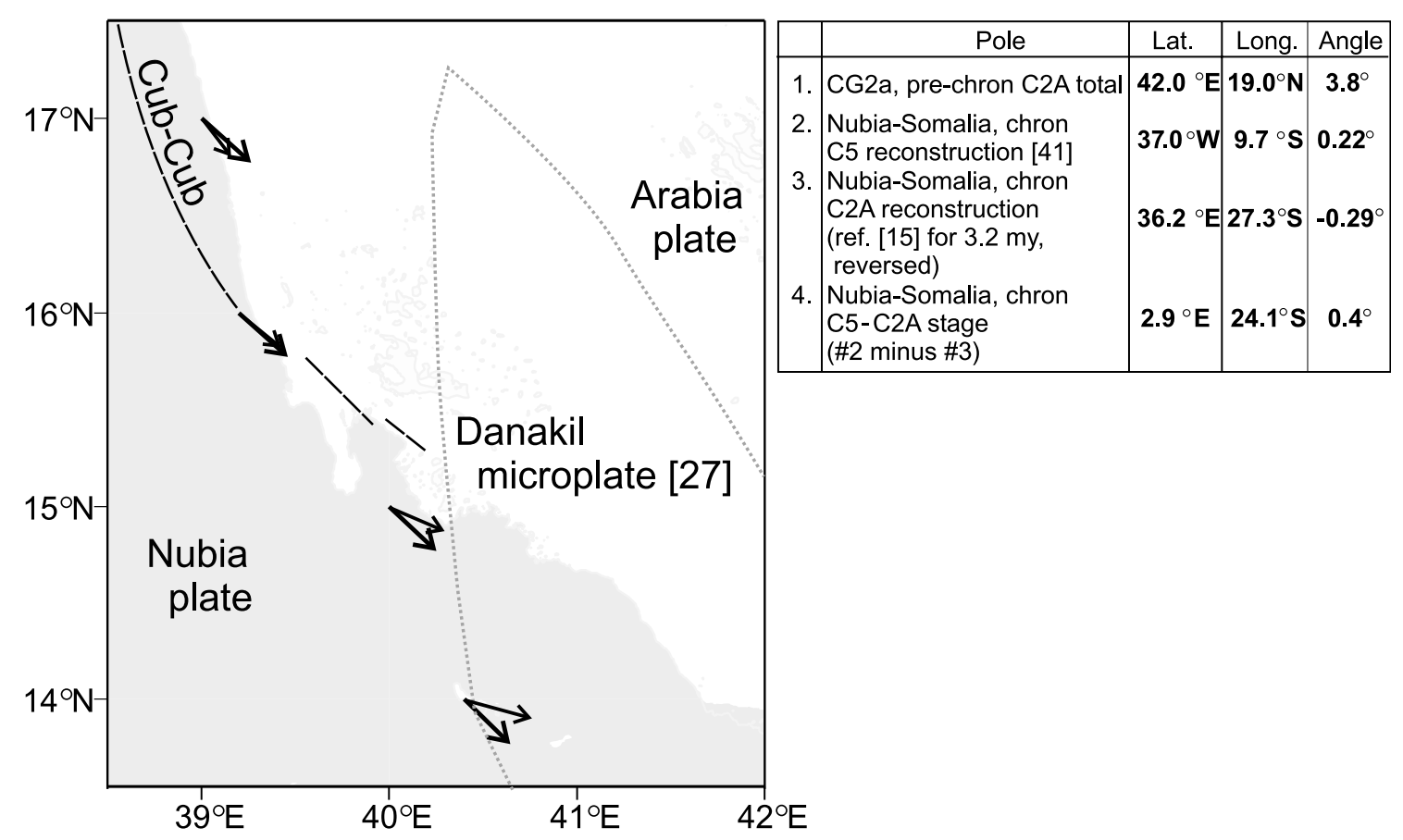

Fig. 9. Comparison of movements about the CG2a pole (thin arrows) and a chron C5-C2A stage pole [27,41] (thick arrows) in northern Afar and the southernmost Red Sea. Dotted outline: present-day approximate boundaries of the Danakil microplate based on scattered seismicity [27], dashed lines: northern part of Oligocene Nubia-Danakil strike-slip boundary (Cub-Cub lineament). Box details the pole parameters. 


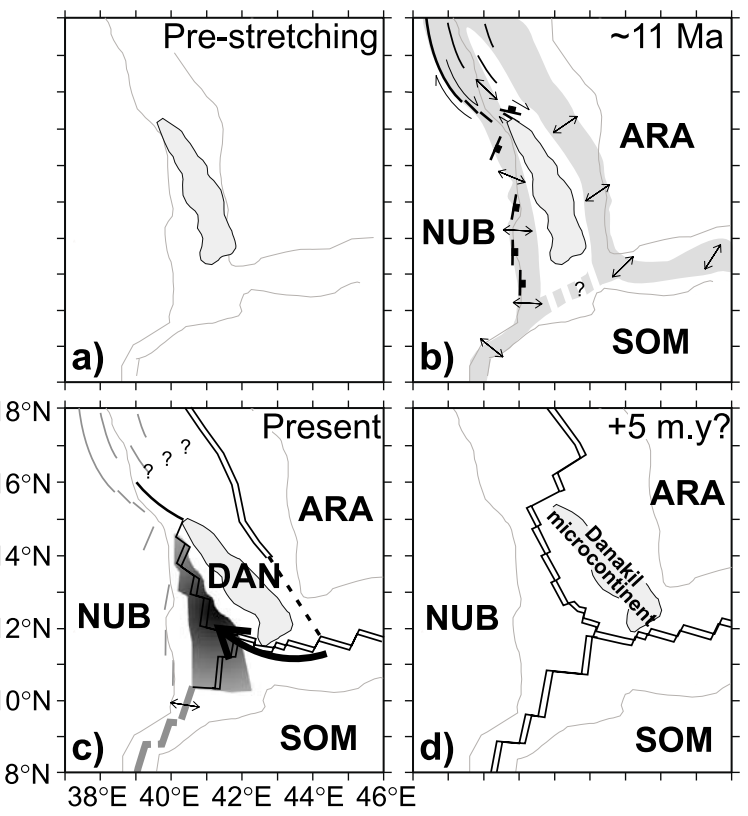

Fig. 10. Cartoon reconstructions featuring the Danakil horst (light grey). (a) Illustrative pre-stretching reconstruction, and (b) 11 Ma. Mid-grey: continental stretching between Nubia (NUB), Somalia (SOM), Arabia (ARA) and Danakil (DAN) plates, dashed grey shading and question mark: newly initiated Danakil-Somalia boundary, black lines: strike-slip faults, black lines with ticks: normal or oblique-slip faults. (c) Today: seafloor spreading (double lines, illustrative only), black arrow: Gulf of Aden rift propagation since $\sim 5 \mathrm{Ma}$, grey lines: inactive faults, shading: approximate extent of $\beta>3$, question marks: line of seismicity (from [27]) at possible northern Danakil-Nubia margin (d) in 5 million years.

\subsection{Evolution of the microplate}

A cartoon representation of movements in the region of the Danakil horst leading to its isolation as a microcontinent is shown in Fig. 10. Fig. 10a shows the region prior to the Oligocene. Danakil's changed shape allows for a tighter reconstruction of its southern parts within the closed bounding Gulf of Aden and Red Sea systems. This is achieved by later stretching of southern Danakil during propagation of the Gulf of Aden rift to form a Danakil-Somalia plate boundary. Because the early history and reconstruction of the bounding systems is a matter of debate, the shape of Danakil shown is illustrative only and is neither intended to enlighten that debate nor to predict the amount of extension associated with propaga- tion of the Gulf of Aden rift. The earliest movements in Afar and the Main Ethiopian rift may have involved both regions opening very slowly about a pole near to the $\mathrm{C} 5-\mathrm{C} 2 \mathrm{~A}$ stage pole, with Danakil as part of the Somalia plate. By $\sim 11 \mathrm{Ma}$ (Fig. 10b) slow movements were about CG2a for Afar, and about the C5-C2A stage pole for the Main Ethiopian rift, initiating a very small relative motion between Somalia and Danakil. By present-day (Fig. 10c) this is pronounced as stretching related to the propagation of the Gulf of Aden rift in southern Afar, and the Danakil horst has assumed its modern shape. The accumulated movement about CG2a implies $\beta>3$ in central and southern Afar, that seafloor spreading is by now active there.

Stratoid lavas in central Afar [44] may be a manifestation at $\sim 4 \mathrm{Ma}$ of the onset of this spreading, also roughly synchronous with the onset of seafloor spreading in the southern Red Sea. If seafloor spreading indeed initiated in this period, the heating and consequent weakening of the lithosphere in Afar and, possibly, nascent ridgepush forces may have promoted self-sustaining accretion, which may explain why the presentday instantaneous pole is applicable to past movements in Afar. An observable corollary of such an event is the westward propagation of the Gulf of Aden rift into Afar. In our view this became necessary as Danakil assumed more rapid easterly movement with respect to Nubia.

So, a possible reason for the recent increase in Danakil-Nubia angular rate is the onset of midoceanic-like accretion in Afar after earlier, slower, rifting. There has been a concomitant decrease in the spreading rate in the southernmost Red Sea [27]. In a regional context these changes may be viewed as an ongoing jump of the post-5 Ma southernmost Red Sea accretionary locus into Afar, and the Danakil microplate as an entity within a double southern Red Sea ridge (e.g. Fig. 10c). Given the short, post-Stratoid, timescale this splitting may actually be an example of a ridge jump in progress.

If along-axis propagation continues into Afar from the Gulf of Aden and the southernmost Red Sea to the Afar ridge jump is achieved, the Gulf of Aden and Red Sea spreading centres will 
connect in a future oceanic crust at a position west of Danakil. We may be seeing the first stages of such an event in the recent tectonic quiescence of the Bab-el-Mandab straits. In such a setting the modern Red Sea spreading centre between $14.5^{\circ} \mathrm{N}$ and $18^{\circ} \mathrm{N}$ would be abandoned and Danakil would become a microcontinent isolated seaward of a deep, narrow, oceanic basin off the southern Arabian Red Sea margin, but on the Arabia plate (Fig. 10d). There are obvious similarities in this to ideas about the isolation of microcontinents on continental margins [4].

\section{Conclusions}

We propose a new model for plate motions in the Afar rift system which is consistent with postPliocene global plate movements and which can explain structural trends in the Danakil-Afar region. Our model implies that independent movement of Danakil relative to Nubia, Arabia and Somalia has been sustained since at least chron $\mathrm{C} 5$, but has become significant since $\sim 5 \mathrm{Ma}$. The approximate position of a Euler pole describing this independence is betrayed by the presence of faults and aligned volcanoes. The earliest independent movements of the Danakil microplate initiated a slow excision from the Somalia plate, as a part of which it may have moved earlier with respect to Nubia. The most recent, statistically significant, independent movement of the Danakil microplate can be related to the onset of oceanictype accretion in Afar that promoted the ongoing propagation of the neighbouring plate boundaries. Thus, microplates can exist in intracontinental plate boundary settings and survive the transition to seafloor spreading. Furthermore, the Afar region may be a suitable test area for continental microplate formation.

\section{Acknowledgements}

Funding for this work was provided by NERC Grant NER/T/2000/00647. Many of the figures were prepared using the Generic Mapping Tools. We are grateful to our colleagues Bekele Abebe,
Chris Elders, Mary Fowler, Tesfaye Korme, Ken McClay, Ingrid Ukstins and Ellen Wolfenden for their support and valuable discussions. [BW]

\section{References}

[1] R.N. Hey, D.F. Naar, M.C. Kleinrock, J.P. Morgan, E. Morales, J.-G. Schilling, Microplate tectonics along a superfast seafloor spreading system near Easter Island, Nature 317 (1985) 320-325.

[2] S.F. Tebbens, S.C. Cande, Southeast Pacific tectonic evolution from Early Oligocene to Present, J. Geophys. Res. 102 (1997) 12061-12084.

[3] M.C. Sengor, J.F. Dewey, Terranology: vice or virtue, in: J.F. Dewey, I.G. Gass, G.B. Curry, N.B.W. Harris, M.C. Sengor (Eds.), Allochthonous Terranes, Cambridge University, Cambridge, MA, 1991, pp. 1-21.

[4] R.D. Müller, C. Gaina, W. Roest, D.L. Hansen, A recipe for microcontinent formation, Geology 29 (2001) 203206.

[5] R.D. Larter, A.P. Cunningham, P.F. Barker, K. Gohl, F.O. Nitsche, 2002. Tectonic evolution of the Pacific margin of Antarctica. 1. Late Cretaceous tectonic reconstructions. J. Geophys. Res., in press.

[6] S.C. Cande, J.M. Stock, R.D. Müller, T. Ishihara, Cenozoic motion between East and West Antarctica, Nature 404 (2000) 145-150.

[7] P.A. Mohr, Major volcano-tectonic lineament in the Ethiopian Rift system, Nature 213 (1967) 664-665.

[8] C. Hofmann, V. Courtillot, G. Féraud, P. Rochette, G. Yirgu, E. Ketefo, R. Pik, Timing of the Ethiopian flood basalt event and implications for plume birth and global change, Nature 389 (1997) 838-841.

[9] X. Le Pichon, J. Francheteau, A plate-tectonic analysis of the Red Sea-Gulf of Aden area, Tectonophysics 46 (1978) 369-406.

[10] V. Courtillot, Propagating rifts and continental breakup, Tectonics 1 (1982) 239-250.

[11] V. Courtillot, F. Achache, F. Landre, N. Bonhommet, R. Montigny, G. Féraud, Episodic spreading and rift propagation: new paleomagnetic and geochronological data from the Afar nascent passive margin, J. Geophys. Res. 89 (1984) 3315-3333.

[12] I.A. Ukstins, P. Renne, E. Wolfenden, J. Baker, M. Menzies, D. Ayalew, Matching conjugate volcanic rifted margins: ${ }^{40} \mathrm{Ar} /{ }^{39} \mathrm{Ar}$ chronostratigraphy of pre- and synrift bimodal flood volcanism in Ethiopia and Yemen, Earth Planet, Sci. Lett. 198 (2002) 289-306.

[13] I. Manighetti, P. Tapponnier, P.Y. Gillot, V. Courtillot, E. Jacques, J.C. Ruegg, G. King, Propagation of rifting along the Arabia-Somalia plate boundary: into Afar, J. Geophys. Res. 103 (1998) 4947-4974.

[14] R. Bilham, R. Bendick, K. Larson, P. Mohr, J. Braun, S. Tesfaye, L. Asfaw, Secular and tidal strain across the Main Ethiopian Rift, Geophys. Res. Lett. 26 (1999) 2789-2792. 
[15] D. Chu, R.G. Gordon, Evidence for motion between Nubia and Somalia along the southwest Indian ridge, Nature 398 (1999) 64-66.

[16] N. Hayward, C. Ebinger, Variations in the along-axis segmentation of the Afar rift system, Tectonics 15 (1996) 244-257.

[17] J. Cochran, A model for development of the Red Sea, Am. Assoc. Petrol. Geol. Bull. 67 (1983) 41-69.

[18] B. Sichler, La biellette danakile: un modèle pour l'évolution géodynamique de l'Afar, Bull. Soc. Geol. Fr. 22 (1980) 925-933.

[19] I. Manighetti, Dynamique des Systèmes Extensifs en Afar, Ph.D. thesis, Inst. de Phys. du Globe de Paris, 1993.

[20] L. Audin, Pénétration de la Dorsale d'Aden dans la Dépression Afar entre 20 et $4 \mathrm{Ma}$, Ph.D. thesis, Inst. de Phys. du Globe de Paris, 1999.

[21] T. Souriot, J.-P. Brun, Faulting and block rotation in the Afar triangle, East Africa: the Danakil 'crank-arm' model, Geology 20 (1992) 911-914.

[22] M. Boccaletti, R. Mazzuoli, M. Bonini, T. Trua, B. Abebe, Plio-Quaternary volcanotectonic activity in the northern sector of the Main Ethiopian rift: relationships with oblique rifting, J. Afr. Earth Sci. 29 (1999) 679698.

[23] P. Tapponnier, R. Armijo, I. Manighetti, V. Courtillot, Bookshelf faulting and horizontal block rotations between overlapping rifts in southern Afar, Geophys. Res. Lett. 17 (1990) $1-4$.

[24] G.D. Acton, S. Stein, Block rotation and continental extension in Afar: a comparison to oceanic microplate systems, Tectonics 10 (1991) 501-526.

[25] G. Acton, A. Tessema, M. Jackson, R. Bilham, The tectonic and geomagnetic significance of paleomagnetic observations from volcanic rocks from central Afar, Earth Planet. Sci. Lett. 180 (2000) 225-241.

[26] B. Collet, H. Taud, J.F. Parrot, F. Bonavia, J. Chorowicz, A new kinematic approach for the Danakil block using a Digital Elevation Model representation, Tectonophysics 316 (2000) 343-357.

[27] D. Chu, R.G. Gordon, Current plate motions across the Red Sea, Geophys. J. Int. 135 (1998) 313-328.

[28] D.A. Hastings, P.K. Dunbar, Development and assessment of the Global Land One-km Base Elevation digital elevation model (GLOBE), ISPRS Arch. 32 (1998) 218221.

[29] S.A. Drury, S.P. Kelley, S.M. Berhe, R.E.Ll. Collier, M. Abraha, Structures related to Red Sea evolution in northern Eritrea, Tectonics 13 (1994) 1371-1380.
[30] N.H. Kenea, C.J. Ebinger, D.C. Rex, Late Oligocene volcanism and extension in the southern Red Sea hills, Sudan, J. Geol. Soc. London 158 (2001) 285-294.

[31] M. Keep, K.R. McClay, Analogue modeling of multiphase rift systems, Tectonophysics 273 (1997) 239-270.

[32] E. Abbate, P. Passerini, L. Zan, Strike-slip faults in a rift area: a transect in the Afar Triangle, East Africa, Tectonophysics 241 (1995) 67-97.

[33] E. Wolfenden, C. Ebinger, I.A. Ukstins, G. Yirgu. Segmentation of a young volcanic passive margin: western margin of the southern Red Sea in Ethiopia, 2002, in preparation.

[34] BP Exploration, Southern Red Sea, Regional review, 1992, Ext. 64264.

[35] I. Manighetti, P. Tapponnier, V. Courtillot, Y. Gallet, E. Jacques, P.-Y. Gillot, Strain transfer between disconnected, propagating rifts in Afar, J. Geophys. Res. 106 (2001) 13613-13665.

[36] M.J. Makris, R. Rihm, Shear controlled evolution of the Red Sea: pull-apart model, Tectonophysics 198 (1991) 441-466.

[37] H.A. Roeser, A detailed magnetic survey of the southern Red Sea, Geol. Jahrb. D13 (1975) 131-153.

[38] R.W. Girdler, P. Styles, Sea-floor spreading in the western Gulf of Aden, Nature 271 (1974) 615-617.

[39] A.Y. Izzeldin, Seismic, gravity and magnetic surveys in the central part of the Red Sea, their interpretation and implications for the structure and evolution of the Red Sea, Tectonophysics 143 (1987) 269-306.

[40] F. Jestin, P. Huchon, J.M. Gaulier, The Somalia plate and the East African Rift System: present-day kinematics, Geophys. J. Int. 116 (1994) 637-654.

[41] J. Lemaux II, R.G. Gordon, J.-Y. Royer, Location of the Nubia-Somalia boundary along the Southwest Indian Ridge, Geology 30 (2002) 339-442.

[42] H. Hebert, C. Deplus, P. Huchon, K. Khanbari, L. Audin, Lithospheric structure of the nascent west Gulf of Aden spreading center inferred from gravity data, J. Geophys. Res. 106 (2001) 26345-26363.

[43] R.S. Stein, P. Briole, J.G. Ruegg, P. Tapponnier, F. Gasse, Contemporary, Holocene and Quaternary deformation of the Asal Rift, Djibouti: implications for the mechanics of slow spreading ridges, J. Geophys. Res. 96 (1991) 21789-21806.

[44] B. Wolde, Spatial and temporal variations in the compositions of Upper Miocene to Recent basic lavas in the northern Main Ethiopian Rift: implications for the causes of Cenozoic magmatism in Ethiopia, Geol. Rundsch. 85 (1996) 380-389. 